\title{
A Case of Primary Peritoneal Hydatidosis
}

\author{
KL Sampath Kumar*
}

MJAFI 2009; 65 : 278-279

Key Words : Hydatid cyst

\section{Introduction}

$\mathrm{H}$ ydatid disease is caused by the larval stage of a dog tapeworm, Echinococcus granulosus. It is endemic in certain parts of India. Liver and lung are the common organs affected by hydatid disease. The peritoneal hydatid disease is rare. The frequency of peritoneal involvement is approximately $13 \%$ [1]. In most of these cases the peritoneal involvement is related to previous surgery for hepatic hydatid disease. In some cases it may be related to traumatic rupture of a hepatic or a splenic hydatid disease. However primary peritoneal involvement without involvement of any other organ in the body is very rare [2]. A case of primary peritoneal hydatidosis is being reported here.

\section{Case Report}

A 49 year old female patient presented to the hospital with the history of irregular menstrual cycles of recent onset. Clinical examination did not reveal any abnormality. However ultrasonography of abdomen revealed multiple hydatid cysts in various stages of development in the abdomen. Even on direct questioning, she did not offer any symptoms related to hydatid cysts. There was no history of close association with dogs. There was no history suggestive of anaphylaxis in the past. The investigations were carried out. There was no eosinophilia. The radiograph of chest was normal. As mentioned earlier, the ultrasonography of abdomen revealed multiple hydatid cysts (Fig. 1).

The patient was advised to take the scolicidal agent in the form of albendazole $400 \mathrm{mg}$ b.i.d orally for six weeks. Ultrasonography of abdomen was repeated. However there was no difference in the size of hydatid cysts or in the number of cysts when compared to the previous ultrasonography. Hence the patient was taken up for exploratory laparotomy with the aim of total extirpation of all the visible hydatid cysts. Laparotomy was done through a supra umbilical midline incision extending below the umbilicus skirting around it. As soon as the peritoneal cavity was opened, multiple hydatid cysts of various sizes were found in the peritoneal cavity (Fig. 2). After taking the necessary precautions like isolating the field of surgery with dark coloured towels soaked in scolicidal agent, one by one all the visible hydatid cysts were excised carefully without causing rupture (Fig. 3). Liver and spleen were examined and there were no tell-tale signs of hydatid cysts. The abdomen was closed without any drain. Postoperative period was uneventful. Histopathological examination confirmed the cysts being hydatid cysts. The patient was advised to take further medical treatment, Tab albendazole $400 \mathrm{mg}$ b.i.d for total 12 weeks, four weeks of three cycles at three week drug free interval periods. At the end of this period, repeat ultrasonography did not reveal any recurrence. When reviewed last, six months after the surgery the patient remained asymptomatic and ultrasonography was also unremarkable. The patient is advised to come for review annually for the next five years.

\section{Discussion}

Hydatid disease is caused by Echinococcus granulosus, a dog tapeworm. The disease is endemic in Asia, South America, and certain parts of Africa and in some Mediterranean countries [1]. The disease is caused by the larval stage of the parasite whose primary host is dog. The life cycle is maintained in nature by dog-sheepdog cycle. Man is an incidental intermediate host. However in man the life cycle of the parasite comes to an end. Man gets infected when the tapeworm ova are ingested either by consuming unwashed and uncooked vegetables or as a result of close contact with an infected dog [2]. Liver ( $75 \%$ of cases) and lungs ( $15 \%$ of cases) are the common organs involved and the peritoneal involvement is very uncommon [3]. Peritoneal hydatidosis is frequently secondary to operative intervention for hepatic hydatid cyst or splenic hydatid cyst. Primary peritoneal hydatidosis is rare and has been reported to occur in only $2 \%$ of all abdominal hydatid disease cases [4]. The mechanism of primary peritoneal involvement is not clear. The dissemination into peritoneal cavity may take place via lymphatic or systemic circulation [5]. The other possibility is due to spontaneous rupture of a superficial hepatic hydatid cyst resulting in extensive

*Head, General Surgery Unit III, Rajiv Gandhi Institute of Medical Sciences, Kadapa-516004 (AP)

Received : 22.07.08; Accepted : 02.04.09

E-mail : sampath68@rediffmail.com 


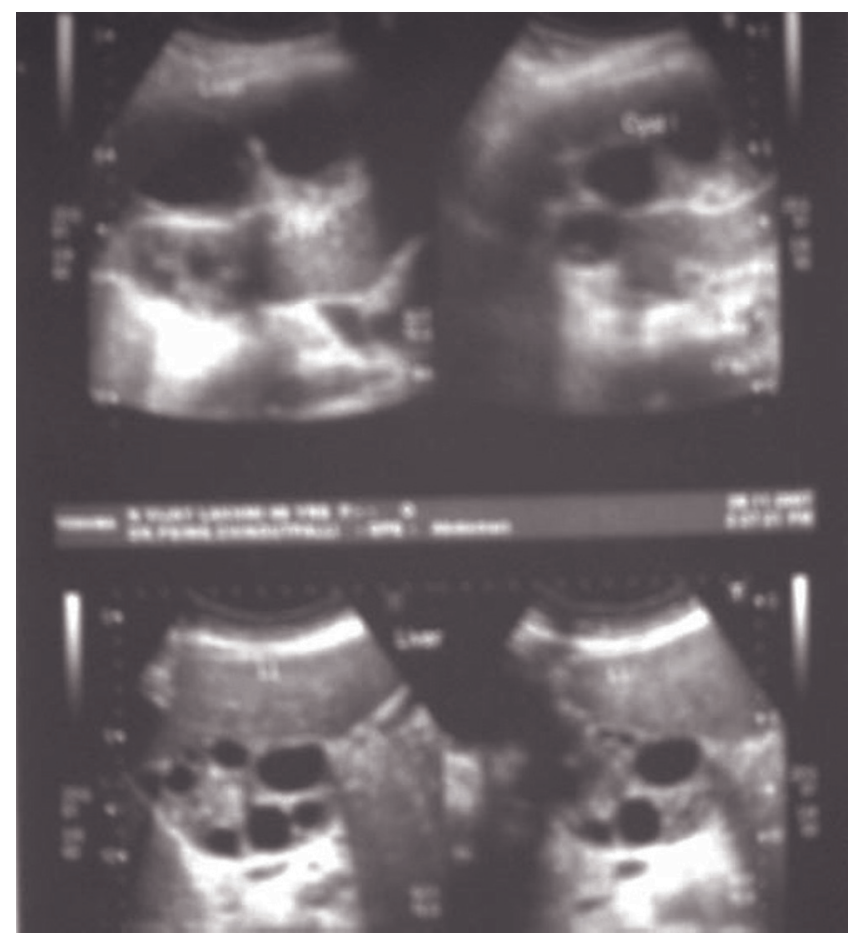

Fig. 1 : Ultrasonogram showing multiple hydatid cysts

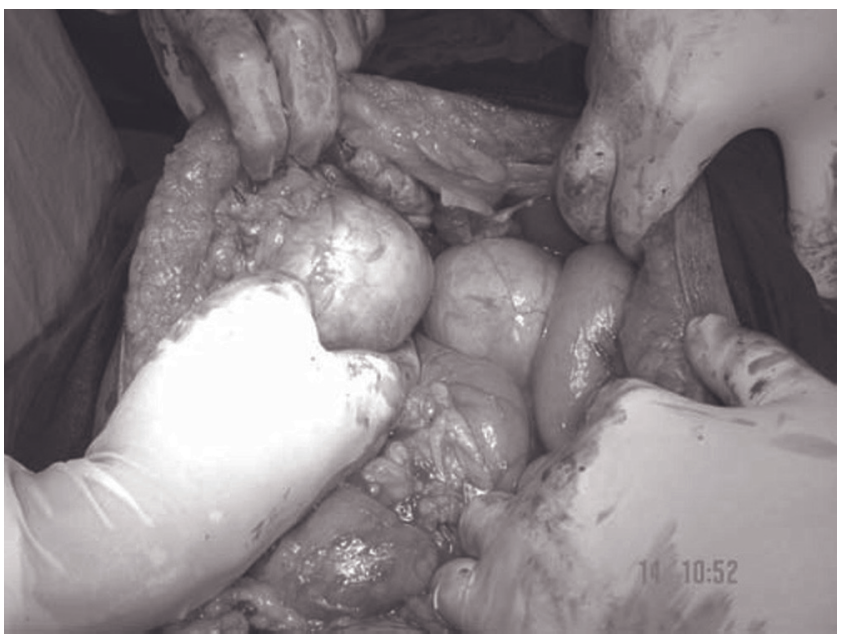

Fig. 2 : Operative photograph showing hydatid cysts

peritoneal involvement.

In most of the cases, the peritoneal hydatid cyst does not produce any symptoms and the diagnosis is made when the patient undergoes ultrasonography for an unrelated cause as in this patient. Ultrasonography is the first line of screening and leads to diagnosis in more than $95 \%$ of cases [6]. CT scan gives better evaluation of hydatid cysts. Serological tests have approximately

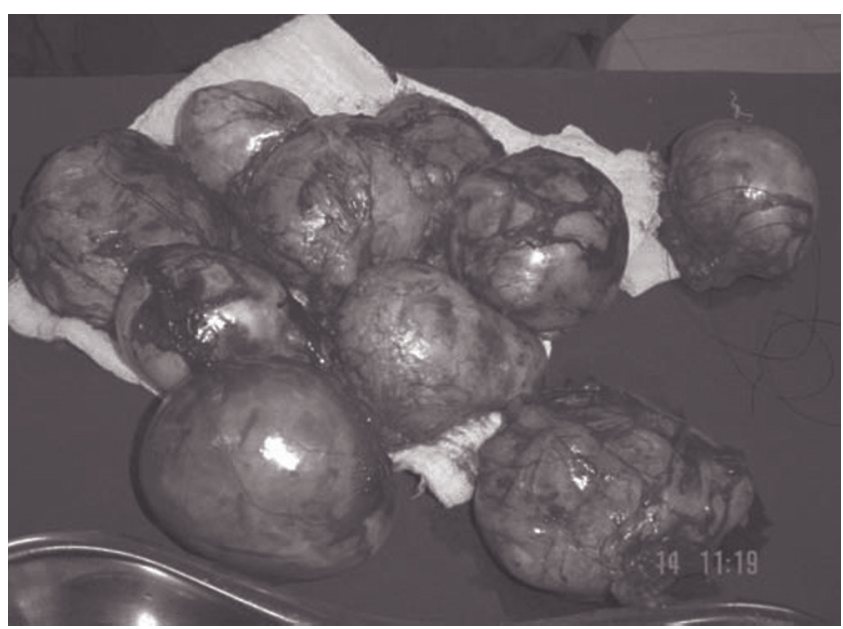

Fig. 3 : Excised hydatid cysts.

$85 \%$ sensitivity [7]. Surgery in the form of complete excision of the cyst is the best curative treatment for peritoneal echinococcosis which was done in this case.

Primary peritoneal hydatidosis is very rare and is seen in $2 \%$ of all abdominal hydatid disease cases. Peritoneal hydatid cyst is usually asymptomatic and remains undiagnosed until ultrasonography examination is done for unrelated symptoms. Careful and complete surgical excision of the cyst is the curative treatment. In extensive involvement, scolicidal agents are helpful to treat small cysts which are invisible to the naked eye.

\section{Conflicts of Interest}

None identified

\section{References}

1. Karavias DD, Vagianos CE, Kakkos SK, Panagopoulis CM. Peritoneal echinococcosis. World J Surg 1996; 20:337-40.

2. Bannister B, Begg N, Gillespie S. Infectious Diseases; Second Edition, Blackwell Science, UK 2000; 506.

3. Prousalidis J, Tzardinoglouk K, Katsokis C, Aletras C. Uncommon sites of hydatid disease. World J Surg 1998; 22:1722.

4. Balik AA, Celebi F, Basoglu M, et al. Intra abdominal extra hepatic echinococcosis. Surg Today 2001; 31: 881-4.

5. Aster-cioglu H, Koidor MA, Toplak O, et al. Isolated meso sigmoid hydatid cyst as an unusual cause of colonic obstruction. Report of a case. Surg Today 2001; 31: 920-2.

6. Lewall DB. Hydatid disease: biology, pathology, imaging and classification. Clin Radiol 1998; 53: 863-74.

7. Gottstein B, Reichen J. Echinococcosis/Hydatidosis: In: Gordon C, Cook, Alimuddin Zumla, editors. Manson's Tropical Diseases. $21^{\text {st }}$ ed. London: WB Saunders 2003; 1561-82. 